\title{
Quantitative Molecular Imaging of Breast Microcalcification Composition using Photon-Counting Spectral Computed Tomography
}

\author{
Tyler E. Curtis and Ryan K. Roeder \\ Department of Aerospace and Mechanical Engineering \\ Bioengineering Graduate Program \\ University of Notre Dame \\ Notre Dame, IN 46556, USA
}

Submitted to: bioRxiv

Keywords: $\quad$ Breast Microcalcifications; Calcium Phosphate; Calcium Oxalate; Hydroxyapatite; Molecular Imaging; Quantitative Material Decomposition; Photon-Counting Spectral Computed Tomography

Correspondence: $\quad$ Ryan K. Roeder, Ph.D., Professor

Department of Aerospace and Mechanical Engineering

Bioengineering Graduate Program

148 Multidisciplinary Research Building

Notre Dame, Indiana 46556

Phone: (574) 631-7003

Email: rroeder@nd.edu

Funding Sources: Kelly Cares Foundation

Martell Family Ph.D. Fellowship, University of Notre Dame

St. Joseph Health System

University of Notre Dame Equipment Renewal and Restoration Program 


\begin{abstract}
Mammographic screening for breast cancer is unable to distinguish molecular differences between hydroxyapatite (HA) microcalcifications ( $\mu$ cals) that are associated with malignancy and calcium oxalate $(\mathrm{CaOx}) \mu \mathrm{cals}$ that are benign. Therefore, the objective of this study was to investigate quantitative material decomposition of model breast $\mu$ cals of clinically-relevant composition and size using spectral photon-counting computed tomography (PCCT). Model $\mu$ cals composed of $\mathrm{HA}, \mathrm{CaOx}$, and dicalcium phosphate (DCP) were treated as materials containing spatially coincident elemental compositions of calcium $(\mathrm{Ca})$, phosphorus $(\mathrm{P})$, and oxygen $(\mathrm{O})$. Elemental decomposition was performed using constrained maximum-likelihood estimation in the image domain. Images were acquired with a commercial, preclinical PCCT system (MARS Bioimaging) with five energy bins selected to maximize counts at low photon energies and spectral differences between $\mathrm{Ca}$ and $\mathrm{P}$. Elemental concentrations of $\mathrm{Ca}$ and $\mathrm{P}$ within the each $\mu$ cal composition were accurately identified and quantified with a root-mean-squared error $<12 \%$. HA and $\mathrm{CaOx} \mu$ cals, $<1 \mathrm{~mm}$ is size, were accurately discriminated by the measured $\mathrm{P}$ content with an area under the receiver operating characteristic curve $(\mathrm{AUC})>0.9$. The mole fraction of $\mathrm{P}, \mathrm{P} /(\mathrm{Ca}+\mathrm{P})$, was able to discriminate all three $\mu$ cal compositions with AUC $>0.8$ for $\mu$ cals $<1 \mathrm{~mm}$ is size and AUC $=1$ for $\mu$ cals $>2 \mathrm{~mm}$ in size. The overall accuracy for the classification of $\mu$ cal types and quantification of $\mathrm{P}$ was robust against different assumptions in the elemental decomposition calibration, but quantification of Ca was improved with assumptions that most accurately accounted for the molar volume of each element within $\mu \mathrm{cal}$ compositions. Thus, PCCT enabled quantitative molecular imaging of breast $\mu \mathrm{cal}$ composition, which is not possible with current clinical molecular imaging modalities.
\end{abstract}




\section{Introduction}

Breast cancer is the most widely diagnosed type of cancer, and the second leading cause of cancerrelated deaths, among women in the United States (Siegel et al. 2019). Early radiographic detection by mammography is currently the best available means for reducing breast cancer mortality (Smith et al. 2019, Van Ourti et al. 2020). Microcalcifications ( $\mu$ cals) are the most common abnormality detected by mammography, coincident with $30-50 \%$ of all breast lesions and $85-95 \%$ of all cases of ductal carcinoma in situ (Cheng et al. 2003, Gülsün et al. 2003, Henrot et al. 2014, Millis et al. 1976). Two types of $\mu$ cals commonly present in breast tissue (Bonfiglio et al. 2018, Frappart et al. 1984, Frappart et al. 1987, Haka et al. 2002). Type I $\mu$ cals are composed of calcium oxalate $(\mathrm{CaOx}), \mathrm{CaC}_{2} \mathrm{O}_{4}$, and are benign. Type II $\mu$ cals are composed of hydroxyapatite (HA), $\mathrm{Ca}_{5}\left(\mathrm{PO}_{4}\right)_{3} \mathrm{OH}$, and are associated with malignant lesions. Both types of $\mu$ cals are detected radiographically by high X-ray contrast relative to adjacent soft tissue. Therefore, radiologists currently use qualitative features - such as the $\mu$ cal morphology, size, anatomic location and clustering - to distinguish suspicious Type II $\mu$ cals from benign Type I $\mu$ cals (Bonfiglio et al. 2018). After the observation of a suspicious $\mu$ cal in a mammogram, a biopsy is required for definitive diagnosis, but malignancy is only confirmed in only $20-30 \%$ of biopsies (Kim et al. 2020, White et al. 2001). Thus, mammographic screening results in false-positives, unnecessary biopsies, and overdiagnosis (Løberg et al. 2015, Oeffinger et al. 2015, Siu 2016).

Spectral or multi-energy X-ray imaging methods - such as dual-energy computed tomography (DECT) or mammography and photon-counting CT (PCCT) - have recently enabled quantitative imaging of material composition by leveraging characteristic differences in X-ray attenuation across the incident photon energy spectrum (Jacobsen et al. 2020, McCollough et al. 2020, Willemink et al. 2018). Conventional CT and mammography utilize an energy integrating 
detector (EID) which sums all photon interactions across the observable energy spectrum into a single image, ignoring spectral and thus material-specific information. DECT partially leverages spectral information by exposing an EID to two different but overlapping photon energy spectra, such that differences in X-ray attenuation can be used to identify (Johnson et al. 2007) and quantify (Yu et al. 2018) material compositions, but material identification in DECT is typically limited to two material components. Assumptions can be made in the material decomposition to allow up to three material components, but can also lead to increased error. Photon-counting detectors (PCDs) enable spectral information to be acquired from a single source spectra in multiple, distinct energy bins by thresholding direct current peaks associated with the energy of photon interactions (Willemink et al. 2018). Therefore, PCCT can identify (Anderson et al. 2010, Cormode et al. 2010) and quantify (Alessio and MacDonald 2013, Cormode et al. 2017, McGinnity et al. 2016, Perrson et al. 2014, Schlomka et al. 2008) multiple discrete and even mixed (Curtis and Roeder 2019, Symons et al. 2017) material compositions simultaneously.

Several recent studies have investigated the feasibility of discriminating calcium compositions associated with breast $\mu$ cals and renal stones using spectral X-ray imaging methods. $\mathrm{HA}$ and $\mathrm{CaOx}$ renal stones, $>3 \mathrm{~mm}$ in size, were identified at an area under the receiver operating characteristic curve (AUC) of $\sim 0.8$ using DECT with either an EID or PCD (Ferrero et al. 2018). The feasibility of discriminating model $\mathrm{HA}$ and $\mathrm{CaOx}$ breast $\mu$ cals was demonstrated by numerical and analytical simulations of dual energy mammography with a PCD (Ghammraoui et al. 2017, 2019, Kim et al. 2019, Martini et al. 2017). Experimental validations reported AUC ranging 0.760.88 (Ghammraoui et al. 2019), or measured differences in an "effective" calcium-to-phosphorus ratio $(\mathrm{Ca} / \mathrm{P})$ with a coefficient of variation ranging $\sim 5-20 \%$ (Martini et al. 2017), for variations in the phantom and $\mu$ cal thickness. Importantly, the preceding dual energy methods all utilized 
relative differences in the measured signal or contrast, normalized to noise or background, between a low and high energy bin or acquisition, and were therefore unable to determine the $\mu$ cal elemental composition. The discrimination of $\mathrm{HA}$ and $\mathrm{CaOx}$ by multi-energy PCCT was investigated by comparing the measured contrast-to-noise ratio across several photon energy bins, but material decomposition was not performed (Kirkbride et al. 2017).

Therefore, the objective of this study was to investigate quantitative material decomposition of model breast $\mu$ cals of clinically-relevant composition and size using PCCT. Model $\mu$ cals composed of HA (type II, associated with malignancy), $\mathrm{CaOx}$ (type I, benign), and dicalcium phosphate (DCP, control) were treated as materials containing mixed elemental compositions of calcium $(\mathrm{Ca})$, phosphorus $(\mathrm{P})$, and oxygen $(\mathrm{O})$. Elemental concentration maps, and the mole fraction of $\mathrm{P}, \mathrm{P} /(\mathrm{Ca}+\mathrm{P})$, was used to identify and discriminate between each type of $\mu \mathrm{cal}$.

\section{Materials and Methods}

\subsection{Homogenous Liquid Phantom}

Elemental decomposition of $\mathrm{Ca}$ and $\mathrm{P}$ was first investigated with a homogeneous liquid phantom containing mixtures of calcium chloride and phosphoric acid in varying molar ratios.

\subsubsection{Calibration and Sample Phantoms}

Calibration phantoms comprising calcium chloride dihydrate, $\mathrm{CaCl}_{2} \cdot 2 \mathrm{H}_{2} \mathrm{O}$ (Sigma Aldrich, $\geq 99.9 \%$ ), and phosphoric acid, $\mathrm{H}_{3} \mathrm{PO}_{4}$ (Sigma Aldrich, > $85 \mathrm{wt} \%$ ) solutions were prepared with 8 concentrations each, ranging 0 to $4.8 \mathrm{M}(192 \mathrm{~g} / \mathrm{L}) \mathrm{Ca}$ and 0 to $4 \mathrm{M}(124 \mathrm{~g} / \mathrm{L}) \mathrm{P}$, respectively, in deionized (DI) water containing $1 \%$ agarose (Thermo Scientific, molecular biology grade) 
(Table 1). Calibration concentrations were chosen to significantly exceed estimated sample concentrations to achieve greater accuracy and less variability in image-based material decomposition by maximizing the signal-to-noise ratio for each component (Curtis and Roeder, 2017). A sample phantom comprising mixtures of calcium chloride and phosphoric acid was prepared at 8 concentrations ranging from 0 to $2.44 \mathrm{M}(97.8 \mathrm{~g} / \mathrm{L}) \mathrm{Ca}$ and $2.17 \mathrm{M}(67.2 \mathrm{~g} / \mathrm{L})$ to $0 \mathrm{M}$ $\mathrm{P}$, respectively, in DI water containing $1 \%$ agarose (Table 1). The calibration phantom was imaged once and the sample phantom was imaged in ten separate acquisitions, to create ten imaging replicates of each mixed composition of $\mathrm{Ca}$ and $\mathrm{P}$. For both the calibration and sample phantoms, Eppendorf tubes (5 mm inner diameter) containing each discrete or mixed composition and concentration were placed in a modular acrylic phantom (35 mm outer diameter) for imaging. A polytetrafluoroethylene screw was present at the center of each phantom as part of a clamping mechanism for holding Eppendorf tubes thin the phantom and was excluded from material decomposition.

\subsubsection{Image Acquisition}

Images were acquired using a commercially-available spectral CT (MARS-12 v.5, MARS Bioimaging Ltd., Christchurch, NZ) equipped with a polychromatic X-ray source operating at $120 \mathrm{kVp}$ with $2 \mathrm{~mm}$ aluminum beam filtration, and a PCD comprising three Medipix 3RX chips with CdZnTe semiconductor sensors utilizing five energy bins in charge summing mode (Ballabriga et al. 2013, Walsh et al. 2013). An evaluation of the X-ray attenuation profiles for elemental Ca and P (Berger et al. 2010, Hubbell and Seltzer 2004) revealed an intersection point at $\sim 44 \mathrm{keV}$ when the thicknesses were selected to achieve equal attenuation across a $20-120 \mathrm{keV}$ photon energy spectrum (Fig. 1). Energy thresholds were therefore selected to create five energy bins at 7-22, 22-32, 32-80, 80-90, and 90-120 keV, such that two bins were placed on either side 
of the Ca-P intersection point in the photon energy spectrum. These energy thresholds served to maximize differences in attenuation rate between $\mathrm{Ca}$ and $\mathrm{P}$ while maximizing signal from the lower energy thresholds. To mitigate the effects of pulse-pileup, the excitation current was set to $18 \mu \mathrm{A}$ and each detector pixel was limited to a mean of 1000 total counts across all energy bins. Images were acquired using a helical scan with 1800 projections per rotation over two rotations and a $100 \mathrm{~ms}$ integration time. Reconstructions (MARS Bioimaging v1.1) were performed with a $200 \mu \mathrm{m}$ isometric voxel size. For representative images, grayscale intensities were converted to Hounsfield units (HU) by internal calibration with air (-1000 HU) and water (0 HU).

\subsubsection{Elemental Decomposition}

Elemental decomposition of spatially coincident $\mathrm{Ca}, \mathrm{P}$, and water was performed using constrained maximum-likelihood estimation (MLE) in the image domain, adapting methods previously demonstrated for spatially discrete (Curtis and Roeder 2017) and coincident (Curtis and Roeder 2019) contrast and tissue compositions. Briefly, MLE was calibrated by a $M \times N$ material basis matrix, where $M$ is the number of energy bins and $N$ is the number of elements or materials to be decomposed. The material basis matrix was established by multiple linear least squares regression of the X-ray attenuation measured in each energy bin versus known concentrations of each material composition in the calibration phantom. The X-ray attenuation was measured as the mean attenuation within a $14.6 \mathrm{~mm}^{3}$ cuboidal volume of interest (VOI) located at the center of each Eppendorf tube in the calibration phantom images. Elemental volume fractions were estimated from the known concentrations of compositions in the calibration phantom based upon the mass and density of $\mathrm{Ca}, \mathrm{P}$, and water.

The volume fraction, or fractional abundance, of materials in each voxel of sample phantom images was determined by MLE using a quadratic programming function, quadprog, in 
MATLAB (v.9.0, Mathworks Inc.) such that solutions to the linear system of equations were constrained to full additivity and non-negativity. The estimated elemental volume fractions of unknown sample compositions were then scaled to millimolar (mM) concentration using the material basis matrix and linear regression model determined from the calibration phantom. The correlation coefficient $\left(R^{2}\right)$ between the measured attenuation values used for calibration of the elemental decomposition of $\mathrm{Ca}$ and $\mathrm{P}$ across all energy bins was calculated by linear least square regression using MATLAB (v.9.0, Mathworks Inc.).

The accuracy of material decomposition was evaluated from sample phantom images using a $17.6 \mathrm{~mm}^{3}$ cuboidal VOI, including 40 slices of the material decomposition, located at the center of each Eppendorf tube. Sensitivity and specificity for detecting $\mathrm{Ca}$ and $\mathrm{P}$ were calculated using the results from the mixed composition solutions. Mixtures containing $1.04 \mathrm{M}(41.7 \mathrm{~g} / \mathrm{L}) \mathrm{Ca}$ and 1.24 M (38.4 g/L) P were selected as true positive VOIs (10 total) for each element. An equal total number of true negative VOIs (10 total) were selected as those containing $0 \mathrm{mM}$ of the element of interest. AUC was calculated by evaluating sensitivity and specificity over a range of concentration thresholds from 0 to $5 \mathrm{M}$ in $0.01 \mathrm{M}$ increments, which exceeded the concentrations within the sample phantom, to determine sets of positive and negative voxels. Sensitivity and specificity were reported at a $0.5 \mathrm{M}$ threshold, which was approximately $20 \%$ of the maximum concentration in any well. The quantitative accuracy of elemental decomposition was evaluated by the root mean squared error (RMSE) of all estimated versus known concentrations for $\mathrm{Ca}$ and $\mathrm{P}$.

\subsection{Calcification Model}

Elemental decomposition of $\mathrm{Ca}, \mathrm{P}$, and $\mathrm{O}$ in clinically-relevant $\mu$ cal compositions was investigated with model $\mu$ cals containing varying ratios, or mole fractions, of $\mathrm{Ca}$ and $\mathrm{P}$ (Table 2). The percentage contribution of each elemental component in $\mathrm{HA}$ and $\mathrm{CaOx}$ to the overall mass and $\mathrm{X}$ - 
ray attenuation was calculated based upon the mole fractions, molecular weights, and NIST attenuation values (Berger et al. 2010, Hubbell and Seltzer 2004) integrated over the photon energy spectrum of the tube emission measured by the PCD (9-120 keV) (Table 2). HA and CaOx exhibit a P:Ca ratio of 3:5 and 0:1, respectively. Therefore, $\mathrm{DCP}(\mathrm{P}: \mathrm{Ca}=1: 1)$ was added as a third $\mu \mathrm{cal}$ composition, and as a positive-control for $\mathrm{P}$, to investigate the ability to decouple the contribution of each element from the overall attenuation of the $\mu$ cal composition.

\subsubsection{Calibration and Sample Phantom}

Model $\mu$ cals comprised discrete concentrations of $\mathrm{HA}, \mathrm{CaOx}$, and DCP placed within a modular phantom. Biomimetic $\mathrm{HA}, \mathrm{Ca} 5\left(\mathrm{PO}_{4}\right) \mathrm{OH}$, crystals were prepared using previously established methods (Roeder et al. 2006). Suspensions of HA or commercially-available DCP, $\mathrm{CaHPO}_{4} \cdot 2 \mathrm{H}_{2} \mathrm{O}$ (Fisher Scientific), crystals were prepared in DI water containing 1\% agarose at a concentration of 0, 3.75, and $7.5 \mathrm{vol} \%$. Suspensions of commercially-available $\mathrm{CaOx}, \mathrm{CaC}_{2} \mathrm{O}_{4} \cdot \mathrm{H}_{2} \mathrm{O}$ (Sigma Aldrich, $\geq 99.9 \%$ ), crystals were also prepared in DI water containing $1 \%$ agarose at a concentration of $0,7.5$, and 11.25 vol $\%$. The concentrations of $\mathrm{CaOx}$ were chosen to match the total attenuation of HA across the overall photon energy spectrum of the polychromatic X-ray source $(\sim 20-120 \mathrm{keV})$. Eppendorf tubes (5 mm inner diameter) containing each discrete composition and concentration ( 7 total) were placed in a modular acrylic phantom (35 $\mathrm{mm}$ outer diameter) for imaging in a single acquisition. A polytetrafluoroethylene screw was present at the center of the phantom as part of a clamping mechanism for holding Eppendorf tubes within the phantom and was excluded from material decomposition. The same phantom was used for both calibration and evaluation. 


\subsubsection{Image Acquisition}

Images were acquired using a commercially-available spectral CT (MARS-12 v.5, MARS Bioimaging Ltd., Christchurch, NZ) equipped with a polychromatic X-ray source operating at $120 \mathrm{kVp}$ with $0.2 \mathrm{~mm}$ copper beam filtration, and a PCD comprising three Medipix $3 \mathrm{RX}$ chips with CdZnTe semiconductor sensors utilizing five energy bins in charge summing mode (Ballabriga et al. 2013, Walsh et al. 2013). Energy thresholds were selected to create five energy bins at 7-25, 25-35, 35-74, 74-87, and 87-120 keV, such that two bins were placed on either side of the Ca-P intersection point in the photon energy spectrum (Fig. 1). These energy thresholds served to maximize differences in attenuation rate between $\mathrm{Ca}$ and $\mathrm{P}$ while maximizing signal from the lower energy thresholds and ensuring adequate count statistics in each energy bin $(\geq 100$ counts) for image reconstruction. To mitigate the effects of pulse-pileup, the excitation current was set to $18 \mu \mathrm{A}$ and each detector pixel was limited to a mean of 1000 total counts across all energy bins. Images were acquired using a circular scan with 1800 projections per rotation over two rotations and a $100 \mathrm{~ms}$ integration time. Reconstructions (MARS Bioimaging v1.1) were performed with a $200 \mu \mathrm{m}$ isometric voxel size. For representative images, grayscale intensities were converted to Hounsfield units (HU) by internal calibration with air $(-1000 \mathrm{HU})$ and water (0 HU).

\subsubsection{Elemental Decomposition}

Elemental decomposition of $\mathrm{Ca}, \mathrm{P}, \mathrm{O}$, and water was performed using constrained MLE in the image domain. Methods previously developed for decomposition of spatially coincident materials were adapted to allow calibration from multiple elements within the same voxel (Curtis and Roeder 2019). Given the known concentration of the $\mu$ cal composition (HA, CaOX, and DCP) in model 
$\mu$ cals, the theoretical volume fraction, $V$, of each $\mu$ cal composition, $j$, and water in model $\mu$ cals was calculated as,

$$
V_{j}^{\prime} \approx \frac{\left(m_{j} / \rho_{j}\right)}{\left(m_{j} / \rho_{j}\right)+\left(m_{\text {water }} / \rho_{\text {water }}\right)}
$$

where $j$ is the $\mu$ cal composition (HA, CaOX, and DCP), $m_{j}$ and $m_{\text {water }}$ are the mass of each $\mu$ cal composition and water, respectively, $\rho_{j}$ and $\rho_{\text {water }}$ are the density of each $\mu$ cal composition and water, respectively, and the volume fraction of water in the model $\mu$ cal is $V_{\text {water }}^{\prime} \approx 1-V_{j}^{\prime}$.

The elemental volume fraction was calculated using two methods. In the first approach, each atom within the crystal structure of each $\mu$ cal composition was assumed to have equal volume, producing an elemental isovolumetric decomposition. The molar fraction, $M$, of each element, $i$, within each $\mu$ cal composition, $j$, was calculated as,

$$
M_{i, j}=\frac{n_{i, j}}{\sum_{1}^{N} n_{i, j}}
$$

where $n_{i, j}$ is the number of moles of element, $i$, present in $\mu$ cal composition, $j$, and $N$ is the total number of elements $(\mathrm{Ca}, \mathrm{P}$, and $\mathrm{O})$. The volume fraction, $V$, of each element, $i$, in each $\mu$ cal ccomposition, $j$, in model $\mu$ cals was subsequently estimated as,

$$
V_{i, j}^{\prime}=V_{j}^{\prime} M_{i, j}
$$

where $V_{j}^{\prime}$ is the volume fraction of the $\mu$ cal composition, $j$, in the model $\mu$ cal calculated from equation (1) and $M_{i, j}$ is the molar fraction of each element, $i$, within each $\mu$ cal composition, $j$, calculated from equation (2).

In the second approach, the true volume fraction of each element within each $\mu \mathrm{cal}$ composition was estimated using atomic radii. The total volume, $v$, of each element, $i$, in each $\mu$ cal composition, $j$, was estimated as,

$$
v_{i, j}=M_{i, j} \frac{4}{3} \pi r_{i}^{3}
$$


where $M_{i, j}$ is the molar fraction of each element, $i$, within each $\mu$ cal composition, $j$, calculated from equation (2) and $r$ is the atomic radius for each element, $i$. Atomic radii were utilized for both ionic bonding of $\mathrm{Ca}(1.26 \AA), \mathrm{P}(0.58 \AA)$, and $\mathrm{O}(1.28 \AA)$, and covalent bonding of $\mathrm{Ca}(1.74 \AA), \mathrm{P}$ (1.06 $\AA$ ), and $\mathrm{O}(0.73 \AA$ ) (Cordero et al. 2008). The volume fraction, $V$, of each element, $i$, within each $\mu$ cal composition, $j$, was estimated as,

$$
V_{i, j}=\frac{v_{i, j}}{\sum_{1}^{N} v_{i, j}}
$$

where $v_{i, j}$ is the total volume of each element, $i$, within each $\mu$ cal composition, $j$, calculated from equation (4) and $N$ is the total number of elements (Ca, $\mathrm{P}$, and $\mathrm{O})$. The volume fraction, $V$, of each element, $i$, for each $\mu$ ncal composition, $j$, in model $\mu$ cals was estimated as,

$$
V_{i, j}^{\prime}=V_{j}^{\prime} V_{i, j}
$$

where $V_{j}^{\prime}$ is the volume fraction of the $\mu$ cal composition, $j$, in the model $\mu$ cal calculated from equation (1) and $V_{i, j}$ is the volume fraction of each element, $i$, within each $\mu$ cal composition, $j$, calculated from equation (5). Water was considered as a wholly separate endgroup for material decomposition. Note that elemental $\mathrm{O}$ and water $\left(\mathrm{H}_{2} \mathrm{O}\right)$ are able to be decomposed as separate endgroups by MLE because the density and attenuation of elemental $\mathrm{O}$ is much greater than that of water.

Elemental decomposition was performed on the same images used for calibration. For each method of elemental decomposition, the volume fraction contributions of $\mathrm{Ca}, \mathrm{P}$ and $\mathrm{O}$ were averaged across a 20 slice volume, assigned to RGB channels, respectively, and mapped for model $\mu$ cals. The mole fraction of $\mathrm{P}, \mathrm{P} /(\mathrm{Ca}+\mathrm{P})$, was also mapped to discriminate all three $\mu$ cal compositions. Images were scaled from 0 to 1.25 times the maximum volume fraction of each element in the calibration matrix. This ensured that brightness and contrast within each image was representative of the overall range for each elemental calibration. 
The accuracy of elemental decomposition, without scaling, was evaluated for elemental isovolume and true volume decompositions. The sensitivity and specificity for discriminating one $\mu$ cal composition from another was calculated for elemental $\mathrm{Ca}, \mathrm{P}$, and $\mathrm{O}$ concentrations, as well as the mole fraction of $\mathrm{P}$. Model $\mu$ cals containing two concentrations of the $\mu$ cal composition of interest were selected as true positive VOIs for each element. An equal total number of true negative VOIs were selected from two concentrations of the other $\mu$ cal compositions. For notation, the true positive $\mu$ cal composition of interest is hereafter listed before the negative $\mu$ cal composition (e.g., HA versus $\mathrm{CaOx}$ ). AUC was calculated by evaluating sensitivity and specificity over a range of thresholds including 0 to 2 times the maximum value measured in the $\mu$ cal composition of interest with 400 equidistant threshold steps, to determine sets of positive and negative voxels. The dimensions (diameter and length) of the evaluation VOI was varied to determine detection limits for accurate $\mu$ cal identification and to evaluate size-dependent discrimination of the $\mu$ cal compositions (Table 3 and Fig. 2). The size of the VOI was varied to include and exceed the size of pathologically-relevant $\mu$ cals. Measured AUC values across all elements and VOIs were compared between calibration methods using a paired $t$-test (MATLAB). The quantitative accuracy of elemental decomposition was evaluated by the root mean squared error (RMSE) of all estimated versus known concentrations for each element using the mean volume fraction values measured from $15.02 \mathrm{~mm}^{3}$ cylindrical VOIs at the center of each sample $(n=7)$. 


\section{Results and Discussion}

\subsection{Homogenous Liquid Phantom}

Photon-counting spectral CT enabled elemental decomposition of P and Ca in mixed, or spatially coincident, compositions of the liquid phantom (Fig. 3) The correlation coefficient of attenuation curves for both $\mathrm{Ca}$ and $\mathrm{P}$ was 0.997 . Nonetheless, small differences in the attenuation curves permitted elemental decomposition (Fig. 3). The mean AUC, measured for both Ca and $\mathrm{P}$ was 0.80, which indicated accurate discrimination of $\mathrm{Ca}$ and $\mathrm{P}$ in mixed compositions. The RMSE of measured concentrations was 0.17 and $0.22 \mathrm{M}$ for $\mathrm{Ca}$ and $\mathrm{P}$, respectively, which was $6.7 \%$ of the maximum Ca concentration and $10.1 \%$ of the maximum P concentration (Fig. 4). Importantly, the RMSE as a percent of the maximum signal for measurement of $\mathrm{Ca}$ and $\mathrm{P}$ concentrations was comparable in magnitude to that previously measured for discrete contrast agents (Curtis and Roeder 2017).

\subsection{Calcification Model}

Adjustments were made in the overall protocol to mitigate reconstruction artifacts that could be caused by low count rates at the detector. A $0.2 \mathrm{~mm}$ copper filter was used in place of the $2 \mathrm{~mm}$ aluminum filter in order to reduce beam hardening artifacts in the lowest bins. Bin widths were also adjusted to have a minimum of 100 counts per bin to ensure count statistics were adequate for reconstruction. The highest thresholds were reduced to enhance counts in the upper bins leading to thresholds of 25, 35, 74 and $87 \mathrm{keV}$. Image projections were acquired using a circular scan. All other parameters remained the same as the previous experiment.

The fractional contribution of each element to the overall attenuation of each crystal composition revealed a significant contribution from oxygen (Table 2). Initial attempts to apply 
the $\mathrm{Ca}$ and $\mathrm{P}$ elemental decomposition from the homogenous liquid phantoms to the calcification models using matching protocol settings resulted in an erroneously high attribution of $\mathrm{P}$ to $\mathrm{CaOx}$ wells. The attenuation from oxygen, which was not accounted for in the elemental decomposition, was erroneously identified as P. Thus, the inclusion of oxygen as a separate element in the calcium crystal compositions proved vital to achieving an accurate elemental decomposition.

Material decomposition using the elemental isovolume, ionic true volume, or the covalent true volume assumption enabled quantitative elemental decomposition of $\mathrm{Ca}, \mathrm{P}$ and $\mathrm{O}$ within each calcium crystal composition (Figs. 5-7). Qualitatively a clear delineation between Type I (CaOx) and Type II (HA) $\mu$ cals was observed based on the P content (Figs. 5d, 6d, and 7d). Moreover, mapping the $\mathrm{P} /(\mathrm{Ca}+\mathrm{P})$ ratio qualitatively showed clear delineation between Type I and Type II $\mu$ cals irrespective of the concentration observed within each well (Figs. 5e, 6e, and 7e). This demonstrated that Type I (CaOx) and Type II (HA) $\mu$ cals were able to be discriminated despite changes in their overall attenuation due to concentration (density). Elemental composition maps produced using the isovolume and ionic true volume assumptions were nearly identical.

Type I $\mu$ cals $(\mathrm{CaOx})$ lack $\mathrm{P}$. Thus, differences in the measured $\mathrm{P}$ content of $\mu$ cals provides a strong positive radiographic marker for identifying $\mathrm{HA}$ versus $\mathrm{CaOx}$. False $\mathrm{P}$ signal was present in the $\mathrm{CaOx}$ crystal composition for both the elemental true volume and elemental isovolume assumptions, albeit at a much lower concentration than the $\mathrm{P}$ concentration observed in HA $\mu$ cals. Moreover, the false signal from $\mathrm{P}$ in $\mathrm{CaOx} \mu$ cals was lower using the covalent true volume fraction calibration (Fig. 7) compared with either the elemental isovolume or the ionic true volume fractions (Figs. 5 and 6). This result suggests that the covalent true volume decomposition was able to more closely approximate the elemental composition of the calcium crystal compositions, most likely because the percent contribution of each element to the overall volume fraction (Table 
4) and X-ray attenuation (Table 2) were more closely matched for the assumption of covalent true volume compared with either elemental isovolume or ionic true volume (Table 5).

Quantitative evaluation of the accuracy of elemental decomposition using the elemental isovolume and covalent true volume assumptions revealed a low quantitative error (RMSE) for all elements when measured against expected values for each element and concentration (Table 6). The greatest deviations were observed in measured oxygen values due to low overall attenuation from the element (Table 2). Coefficients of determination $\left(R^{2}\right)$ above 0.7 for $\mathrm{Ca}$ and $\mathrm{P}$ were achieved across a 1:1 regression of the dataset onto the calibration matrix. The quantitative accuracy $\left(R^{2}\right.$ and RMSE) of P content did not appear to be significantly affected by the assumption of the elemental decomposition (Table 6). This result suggests that the quantitative elemental decomposition was robust against large fluctuations in volume fraction values assigned for calibration (Table 4). RMSE was increased and $R^{2}$ decreased for $\mathrm{Ca}$, with an opposite effect observed for oxygen when the covalent true volume calibration was compared to the elemental isovolume calibration (Table 6). The estimated contribution of $\mathrm{Ca}$ to the overall volume of each calcium crystal composition was lower within the covalent true volume calibration (Table 4). Thus, the variability of the attenuation within each model $\mu$ cal likely had a greater impact on the quantitative accuracy of the covalent true volume decomposition compared with the elemental isovolume decomposition. However, reconstruction artifacts were not accounted for in this analysis and additional imaging replicates are required to confirm this interpretation.

Quantitative evaluation of the effect of the VOI on AUC revealed common trends between the elemental isovolume decomposition (Fig. 5), the ionic true volume decomposition (Fig. 6) and the covalent true volume decomposition (Fig. 7). In all decompositions, oxygen content was ineffective $(\mathrm{AUC}=0.5)$ for the delineation of $\mathrm{HA}$ from either $\mathrm{CaOx}$ or DCP, and exhibited 
moderate ability to delineate $\mathrm{CaOx}$ from DCP. The inability of the oxygen content to accurately separate DCP and HA was due to only a $2 \%$ difference in the fractional contribution of $\mathrm{O}$ to the overall attenuation of DCP and HA (Table 2). In preliminary studies, cross-contamination was observed in the measurement of $\mathrm{P}$ and $\mathrm{O}$. Thus, the higher contribution of $\mathrm{P}$ to the DCP signal may have aided in the delineation of DCP from $\mathrm{CaOx}$ using measurements of the oxygen content.

Importantly, the $\mathrm{P} /(\mathrm{Ca}+\mathrm{P})$ ratio was the only metric that provided a significant positive indicator $(\mathrm{AUC}>0.8)$ for the delineation of all three calcium crystal compositions, regardless of the calibration method used. This was due, in part, to the concentration independency of the $\mathrm{P} /(\mathrm{Ca}+\mathrm{P})$ ratio. All other metrics required the exact concentration of the element within the crystal structure to be evaluated using AUC. Multiple concentrations of each calcium crystal composition were used for analysis and lower concentrations of each crystal were less likely to surpass the thresholds selected for evaluation of specificity and sensitivity, causing AUC to fall below 0.8 . The only exception to this was the comparison of P-containing crystal compositions, DCP and HA, to $\mathrm{CaOx}$ which lacks $\mathrm{P}$, using the measured $\mathrm{P}$ content. In this case, the measured signal from $\mathrm{P}$ in $\mathrm{CaOx} \mu \mathrm{cals}$ was merely a consistent background level of erroneous signal (noise) which was substantially lower than the P content measured for either DCP or HA $\mu$ cals (Figs. 5 and 7). Consequently, all concentrations of $\mathrm{CaOx}$ were able to be accurately thresholded from all concentrations of DCP and HA using the P content for all assumptions used in the elemental decomposition. Thus, the use of the $\mathrm{P}$ content for analysis in the $\mathrm{P} /(\mathrm{Ca}+\mathrm{P})$ ratio enabled accurate discrimination of all three calcium crystal compositions using all elemental decomposition calibrations.

The AUC for elemental isovolume, ionic true volume, and covalent true volume decompositions exhibited the greatest variability when HA was included in the analysis (Figs. 5- 
7). DCP and $\mathrm{CaOx}$ presented the largest differences in $\mathrm{P}$ content (Table 2) and were therefore more readily identified using $\mathrm{P}$ content and $\mathrm{P} /(\mathrm{Ca}+\mathrm{P})$. HA exhibits $\mathrm{P}$ content in between that of $\mathrm{CaOx}$ and DCP, and was therefore the most difficult to separate from either DCP or CaOx. Thus, identification of HA was more dependent on the measured Ca content. The discrimination of HA versus $\mathrm{CaOx}$ or DCP using the measured $\mathrm{Ca}$ from the elemental isovolume and ionic true volume assumptions trended towards a distinct separation (AUC $=0.8$ and 0.2 , respectively) (Figs. 5 and 6), while the same evaluation using the covalent true volume assumption trended towards an inability to discriminate HA (AUC=0.5) (Fig. 7). The percent contribution of $\mathrm{Ca}$ to both elemental isovolume fraction and ionic volume fraction exhibited approximately a 30 and 52 percent difference for HA versus DCP and $\mathrm{CaOx}$, respectively (Table 4). Conversely, the covalent true volume fractional contribution of $\mathrm{Ca}$ exhibited an 8 and 12 percent difference for $\mathrm{HA}$ versus $\mathrm{CaOx}$ and DCP, respectively (Table 4). Therefore, the elemental isovolume and ionic true volume allowed a greater relative dynamic range for evaluating Ca volume fraction between the calcium crystal compositions, allowing more discrete thresholding of the Ca volume fraction for discriminating the HA $\mu$ cals. Notably though, a paired $t$-test of the AUC results comparing each elemental decomposition revealed that there were no significant differences in AUC across all calcium crystal composition pairs $(p=0.86)$. Thus, major variations in the calibration did not significantly impact the overall capability of the image-based elemental decomposition to perform classification tasks for each calcium crystal composition. This result suggests that the image-based elemental decomposition was robust to fluctuations in the volume fractions of the calibration used. Therefore, elemental calibration can be readily implemented for discrimination of calcium crystal compositions. 
Finally, to be readily applicable in a clinical setting Type I (CaOx) and Type II (HA) $\mu$ cals must be able to be discriminated at a maximum dimension not exceeding $1 \mathrm{~mm}$ with an AUC > 0.8. AUC for the $\mathrm{P} /(\mathrm{Ca}+\mathrm{P})$ ratio exceeded 0.8 within this clinical size range (Figs. 5-7). Therefore, the $\mathrm{P} /(\mathrm{Ca}+\mathrm{P})$ ratio was able to discriminate a variety of calcium crystal compositions, independent of their concentration. However, the elemental volume fraction of $\mathrm{P}$ provided stronger discrimination of Type I (CaOx) and Type II (HA) $\mu$ cals at the smallest VOI analyzed, (AUC $\geq$ 0.8), because $\mathrm{CaOx}$ lacks $\mathrm{P}$ content (Table 2, Figs. 5-7). Therefore, the $\mathrm{P}$ content is recommended for absolute discrimination of Type I versus Type II $\mu$ cals, while the $\mathrm{P} /(\mathrm{Ca}+\mathrm{P})$ ratio can be more generally applied to identify various calcium crystal compositions containing distinct P:Ca ratios.

Classification of $\mathrm{HA}$ and $\mathrm{CaOx}$ was investigated previously using the MARS Bioimaging photon-counting spectral CT (Kirkbride et al. 2017). The attenuation profiles of HA and CaOx at low energy thresholds of $15,22,29$, and $36 \mathrm{keV}$ and a varied tube potential of 50,80 and $110 \mathrm{kVp}$ were evaluated by a comparative contrast to noise ratio (CNR) to differentiate Type I and Type II $\mu$ cals (Kirkbride et al. 2017). The attenuation of $\mathrm{CaOx}$ at a set concentration of $2000 \mathrm{mg} / \mathrm{ml}$ was compared to varying concentrations of HA $(54.3,211.7,808.5,1169.3$ and $2000 \mathrm{mg} / \mathrm{ml})$ within each energy bin. However, the attenuation profiles of $\mathrm{HA}$ and $\mathrm{CaOx}$ were difficult to differentiate because the overall attenuation of each is dominated by the calcium signal (Table 2). Therefore, the reliability of material separation was dependent on the concentration of the HA measured, with lower concentrations exhibiting less overlap in attenuation compared to $\mathrm{CaOx}$. If applied to material decomposition, variability in the density of the $\mu$ cal would change the accuracy of the material decomposition. The this study, we circumvented this problem by performing elemental decomposition of $\mathrm{Ca}, \mathrm{P}$, and $\mathrm{O}$. 


\section{Conclusions}

Utilizing multiple assumptions for calibration, photon-counting spectral CT and elemental decomposition by MLE in the image domain accurately identified and quantified spatially coincident compositions of $\mathrm{Ca}$ and $\mathrm{P}$ within three calcium crystal compositions (RMSE $<12 \%$ ). Pathologically-relevant Type I (CaOx) and Type II (HA) $\mu$ cals were accurately discriminated $(\mathrm{AUC}>0.8)$ at a clinically-relevant size (max dimension $<1 \mathrm{~mm})$. Thus, in spite of variation in material calibration, elemental decomposition in the image domain using photon-counting spectral CT enabled quantitative molecular imaging of calcium crystal compositions, for the discrimination of Type I and Type II $\mu$ cals under conditions suitable for imaging, which has not been previously demonstrated. If translated to clinical spectral photon-counting mammography, the methods of this study have the potential to reduce the number of false-positives, unnecessary biopsy procedures, and overdiagnosis by mammographic screening.

\section{Acknowledgments}

This research was supported by grants from the Kelly Cares Foundation, St. Joseph Health System, and the University of Notre Dame Equipment Renewal and Restoration Program. TEC was supported by the Martell Family Ph.D. Fellowship at University of Notre Dame. The authors acknowledge the Notre Dame Center for Environmental Science and Technology (CEST) for ICPOES and the Notre Dame Integrated Imaging Facility (NDIIF). 


\section{References}

Alessio AM and MacDonald LR 2013 Quantitative material characterization from multi-energy photon counting CT Med. Phys. $\mathbf{4 0} 031108$

Anderson NG, Butler AP, Scott NJ, Cook NJ, Butzer JS, Schleich N, Firsching M, Grasset R, De Ruiter N, Campbell M and Butler PH 2010 Spectroscopic (multi-energy) CT distinguishes iodine and barium contrast material in mice Eur. Radiol. 20 2126-34

Ballabriga R, Alozy J, Blaj G, Campbell M, Fiederle M, Frojdh E, Heijne EH, Llopart X, Pichotka M, Procz S and Tlustos L 2013 The Medipix3RX: a high resolution, zero dead-time pixel detector readout chip allowing spectroscopic imaging J. Instrum. 8 C02016

Berger MJ, Hubbell JH, Seltzer SM, Chang J, Coursey JS, Sukumar R, Zucker DS and Olsen K 2010 XCOM: Photon Cross Section Database (version 1.5), National Institute of Standards and Technology, Gaithersburg, MD, available at http://physics.nist.gov/xcom

Bonfiglio R, Scimeca M, Toschi N, Pistolese CA, Giannini E, Antonacci C, Ciuffa S, Tancredi V, Tarantino U and Albonici L 2018 Radiological, histological and chemical analysis of breast microcalcifications: diagnostic value and biological significance J. Mammary Gland Biol. Neoplasia 23 89-99

Cheng H-D, Cai X, Chen X, Hu L and Lou X 2003 Computer-aided detection and classification of microcalcifications in mammograms: a survey Pattern Recognit. 36 2967-91

Cordero B, Gómez V, Platero-Prats AE, Revés M, Echeverría J, Cremades E, Barragán F and Alvarez S 2008 Covalent radii revisited Dalton Trans. (21) 2832-8

Cormode DP, Roessl E, Thran A, Skajaa T, Gordon RE, Schlomka J-P, Fuster V, Fisher EA, Mulder WJ and Proksa R 2010 Atherosclerotic plaque composition: analysis with multicolor CT and targeted gold nanoparticles Radiology $\mathbf{2 5 6} 774-82$ 
Cormode DP, Si-Mohamed S, Bar-Ness D, Sigovan M, Naha PC, Balegamire J, Lavenne F, Coulon P, Roessl E and Bartels M 2017 Multicolor spectral photon-counting computed tomography: in vivo dual contrast imaging with a high count rate scanner Sci. Rep. 74784

Curtis TE and Roeder RK 2017 Effects of calibration methods on quantitative material decomposition in photon-counting spectral computed tomography using a maximum $a$ posteriori estimator Med. Phys. 44 5187-97

Curtis TE and Roeder RK 2019 Quantification of multiple mixed contrast and tissue compositions using photon-counting spectral computed tomography J. Med. Imaging 6013501

Ferrero A, Gutjahr R, Halaweish AF, Leng S, McCollough CH 2018 Characterization of urinary stone composition by use of whole-body, photon-counting detector CT Acad. Radiol. 25 12706

Frappart L, Boudeulle M, Boumendil J, Lin HC, Martinon I, Palayer C, Mallet-Guy Y, Raudrant D, Bremond A and Rochet Y 1984 Structure and composition of microcalcifications in benign and malignant lesions of the breast: study by light microscopy, transmission and scanning electron microscopy, microprobe analysis, and X-ray diffraction Hum. Pathol. 15 880-9

Frappart L, Remy I, Lin HC, Bremond A, Raudrant D, Grousson B and Vauzelle J 1987 Different types of microcalcifications observed in breast pathology Virchows Arch. A Pathol. Anat. Histopathol. 410 179-87

Ghammraoui B and Glick SJ 2017 Investigating the feasibility of classifying breast microcalcifications using photon-counting spectral mammography: a simulation study, Med. Phys. 44 2304-11

Ghammraoui B, Makeev A, Zidan A, Alayoubi A and Glick SJ 2019 Classification of breast microcalcifications using dual-energy mammography J. Med. Imaging 6013502 
Gülsün M, Demirkazık FB and Arıyürek M 2003 Evaluation of breast microcalcifications according to Breast Imaging Reporting and Data System criteria and Le Gal's classification Eur. J. Radiol. $47227-31$

Haka AS, Shafer-Peltier KE, Fitzmaurice M, Crowe J, Dasari RR and Feld MS 2002 Identifying microcalcifications in benign and malignant breast lesions by probing differences in their chemical composition using Raman spectroscopy Cancer Res. 62 5375-80

Henrot P, Leroux A, Barlier C and Génin P 2014 Breast microcalcifications: the lesions in anatomical pathology Diagn. Interv. Imaging 95 141-52

Hubbell JH, Gimm HA and Overbo I 1980 Pair, triplet, and total atomic cross sections (and mass attenuation coefficients) for $1 \mathrm{MeV}-100 \mathrm{GeV}$ photons in elements $\mathrm{Z}=1$ to $100 \mathrm{~J}$. Phys. Chem. Ref. Data 9 1023-148

Jacobsen MC, Thrower SL, Ger RB, Leng S, Court LE, Brock KK, Tamm EP, Cressman EN, Cody DD and Layman RR 2020 Multi-energy computed tomography and material quantification: Current barriers and opportunities for advancement Med. Phys. in press

Johnson TRC, Krauss B, Sedlmair M, Grasruck M, Bruder H, Morhard D, Fink C, Weckbach S, Lenhard M, Schmidt B, Flohr T, Reiser MF, Becker CR 2007 Material differentiation by dual energy CT: Initial experience Eur. Radiol. 17 1510-17

Kim H, Lee M, Kim D, Lee D and Kim HJ 2019 Evaluation of photon-counting spectral mammography for classification of breast microcalcifications Radiat. Phys. Chem. 162 39-47

Kim HE, Kim HH, Han BK, Kim KH, Han K, Nam H, Lee EH and Kim EK 2020 Changes in cancer detection and false-positive recall in mammography using artificial intelligence: a retrospective, multireader study. Lancet Digit. Health 2 e138-48. 
Kirkbride TE, Raja AY, Müller K, Bateman CJ, Becce F and Anderson NG 2017 Discrimination between calcium hydroxyapatite and calcium oxalate using multienergy spectral photoncounting CT Am. J. Roentgenol. 209 1088-92

Løberg M, Lousdal ML, Bretthauer M and Kalager M 2015 Benefits and harms of mammography screening Breast Cancer Res. 1763

Martini N, Koukou V, Fountos G, Michail C, Bakas A, Kandarakis I, Speller R and Nikiforidis G 2017 Characterization of breast calcification types using dual energy x-ray method Phys. Med.

Biol. 62 7741-64

McCollough CH, Boedeker K, Cody D, Duan X, Flohr T, Halliburton S, Hsieh J, Layman R, Pelc NJ 2020 Principles and applications of multi-energy CT: Report of AAPM task group 291 Med. Phys. in press.

McGinnity TL, Dominguez O, Curtis TE, Nallathamby PD, Hoffman AJ and Roeder RK 2016 Hafnia $\left(\mathrm{HfO}_{2}\right)$ nanoparticles as an X-ray contrast agent and mid-infrared biosensor Nanoscale $813627-37$

Millis RR, Davis R and Stacey A 1976 The detection and significance of calcifications in the breast: a radiological and pathological study Brit. J. Radiol. 49 12-26

Oeffinger KC, Fontham ET, Etzioni R, Herzig A, Michaelson JS, Shih YC, Walter LC, Church TR, Flowers CR, LaMonte SJ and Wolf AM 2015 Breast cancer screening for women at average risk: 2015 guideline update from the American Cancer Society JAMA 314 1599-614 Perrson M, Huber B, Karlsson S, Liu X, Chen H, Xu C, Yveborg M, Bornefalk H and Danielsson M 2014 Energy-resolved CT imaging with a photon-counting silicon-strip detector Phys. Med. Biol. 59 6709-27 
Roeder RK, Converse GL, Leng H and Yue W 2006 Kinetic effects on hydroxyapatite whiskers synthesized by the chelate decomposition method J. Am. Ceram. Soc. 89 2096-104

Schlomka J, Roessl E, Dorscheid, R, Dill S, Martens G, Istel T, Bäumer C, Herrmann C, Steadman R and Zeitler G 2008 Experimental feasibility of multi-energy photon-counting K-edge imaging in pre-clinical computed tomography Phys. Med. Biol. 53 4031-47

Siegel RL, Miller KD and Jemal A 2019 Cancer statistics, 2019 Cancer J. Clin. 69 7-34

Siu AL 2016 Screening for breast cancer: US preventive services task force recommendation statement Ann. Intern. Med. 164 279-96.

Smith RA, Andrews KS, Brooks D, Fedewa SA, Manassaram-Baptiste D, Saslow D and Wender RC 2019 Cancer screening in the United States, 2019: A review of current American Cancer Society guidelines and current issues in cancer screening Cancer J. Clin. 69 184-210

Symons R, Krauss B, Sahbaee P, Cork TE, Lakshmanan MN, Bluemke DA and Pourmorteza A 2017 Photon-counting CT for simultaneous imaging of multiple contrast agents in the abdomen: An in vivo study Med. Phys. 44 5120-27

Van Ourti T, O'Donnell O, Koç H, Fracheboud J and de Koning HJ 2020 Effect of screening mammography on breast-cancer mortality: Quasi-experimental evidence from rollout of the Dutch population-based program with 17-year follow-up of a cohort Int. J. Cancer $1462201-$ 2208

Walsh MF, Nik SJ, Procz S, Pichotka M, Bell ST, Bateman CJ, Doesburg RMN, Ruiter ND, Chernoglazov AI, Panta RK, Butler APH and Butler PH 2013 Spectral CT data acquisition with Medipix3.1 J. Instrum. 8 P10012

Willemink MJ, Persson M, Pourmorteza A, Pelc NJ and Fleischmann D 2018 Photon-counting CT: Technical principles and clinical prospects Radiology 289 293-312 
bioRxiv preprint doi: https://doi.org/10.1101/2020.09.16.300509; this version posted September 18, 2020. The copyright holder for this preprint (which was not certified by peer review) is the author/funder, who has granted bioRxiv a license to display the preprint in perpetuity. It is made available under aCC-BY 4.0 International license.

White RR, Halperin TJ, Olson Jr JA, Soo MS, Bentley RC and Seigler HF 2001 Impact of coreneedle breast biopsy on the surgical management of mammographic abnormalities Ann. Surg. $233769-77$

Yu L, Ren L, Li Z, Leng S and McCollough CH 2018 Dual-source multienergy CT with triple or quadruple x-ray beams J. Med. Imaging 5033502 


\section{Tables}

Table 1. Discrete and mixed concentrations of $\mathrm{Ca}$ and $\mathrm{P}$ within the homogenous liquid calibration and sample phantoms, respectively.

\begin{tabular}{c|c|cccccccc}
\hline Phantom & Component & \multicolumn{8}{|c}{ Concentrations (M) } \\
\hline \multirow{2}{*}{$\begin{array}{c}\text { Calibration } \\
\text { (discrete Ca and P) }\end{array}$} & $\mathrm{Ca}$ & 0 & 0.69 & 1.37 & 2.05 & 2.74 & 3.43 & 4.11 & 4.80 \\
\cline { 2 - 9 } & $\mathrm{P}$ & 0 & 0.57 & 1.14 & 1.71 & 2.29 & 2.86 & 3.42 & 4.00 \\
\hline $\begin{array}{c}\text { Sample } \\
\text { (mixed Ca and P) }\end{array}$ & $\mathrm{Ca}$ & 2.44 & 2.09 & 1.74 & 1.39 & 1.04 & 0.70 & 0.35 & 0 \\
& $\mathrm{P}$ & 0 & 0.31 & 0.62 & 0.93 & 1.24 & 1.55 & 1.86 & 2.17 \\
\hline
\end{tabular}

Table 2. Percent contribution of each element to the overall moles, mass, and X-ray attenuation of each $\mu$ cal composition.

\begin{tabular}{c|cc|ccccc}
\hline & $\mu$ cal & Composition & $\mathrm{Ca}$ & $\mathrm{P}$ & $\mathrm{O}$ & $\mathrm{H}$ & $\mathrm{C}$ \\
\hline \multirow{3}{*}{$\begin{array}{c}\text { Mole } \\
\text { Percent }\end{array}$} & $\mathrm{CaOx}$ & $\mathrm{CaC}_{2} \mathrm{O}_{4}$ & 14 & 0 & 57 & 0 & 29 \\
& $\mathrm{HA}$ & $\mathrm{Ca}_{5}\left(\mathrm{PO}_{4}\right)_{3} \mathrm{OH}$ & 23 & 14 & 59 & 5 & 0 \\
& $\mathrm{DCP}$ & $\mathrm{CaHPO}_{4}$ & 14 & 14 & 57 & 14 & 0 \\
\hline \multirow{3}{*}{$\begin{array}{c}\text { Mass } \\
\text { Percent }\end{array}$} & $\mathrm{CaOx}$ & $\mathrm{CaC}_{2} \mathrm{O}_{4}$ & 24 & 0 & 59 & 2 & 15 \\
& & & 31 & 0 & 50 & 0 & 19 \\
& $\mathrm{HA}$ & $\mathrm{Ca}_{5}\left(\mathrm{PO}_{4}\right)_{3} \mathrm{OH}$ & 40 & 18 & 41 & 0 & 0 \\
\hline \multirow{3}{*}{$\begin{array}{c}\text { Attenuation } \\
\text { Percent }\end{array}$} & $\mathrm{DCP}$ & $\mathrm{CaHPO}_{4}$ & 29 & 23 & 47 & 1 & 0 \\
& $\mathrm{CaOx}$ & $\mathrm{CaC}_{2} \mathrm{O}_{4}$ & 82 & 0 & 16 & 0 & 2 \\
& DCP & $\mathrm{Ca}_{5}\left(\mathrm{PO}_{4}\right)_{3} \mathrm{OH}$ & 78 & 16 & 7 & 0 & 0 \\
\hline
\end{tabular}


Table 3. Variation in the VOI dimensions used for evaluating the accuracy of elemental decomposition.

\begin{tabular}{ccccc}
\hline ID & Dimension Limit $(\mathrm{mm})$ & Volume $\left(\mathrm{mm}^{3}\right)$ & Number of VOIs & Total Volume $\left(\mathrm{mm}^{3}\right)$ \\
\hline 0 & 0.20 & 0.01 & 80 & 0.64 \\
1 & 0.60 & 0.17 & 40 & 6.79 \\
2 & 1.00 & 0.79 & 20 & 15.71 \\
3 & 1.40 & 2.16 & 12 & 25.86 \\
4 & 1.80 & 4.58 & 8 & 36.64 \\
5 & 2.20 & 8.36 & 8 & 66.90 \\
6 & 2.60 & 13.80 & 4 & 55.22 \\
7 & 3.00 & 21.21 & 4 & 84.82 \\
8 & 3.40 & 30.87 & 4 & 123.48 \\
9 & 3.80 & 43.10 & 4 & 172.39 \\
10 & 4.20 & 58.19 & 4 & 232.75 \\
\hline
\end{tabular}

Table 4. Percent contribution of each element to the overall volume fraction of each calcium crystal composition.

\begin{tabular}{cccc|ccc|ccc}
\hline & \multicolumn{2}{c|}{ Elemental Isovolume } & \multicolumn{3}{c|}{ Ionic True Volume } & \multicolumn{3}{c}{ Covalent True Volume } \\
& $\mathrm{Ca}$ & $\mathrm{P}$ & $\mathrm{O}$ & $\mathrm{Ca}$ & $\mathrm{P}$ & $\mathrm{O}$ & $\mathrm{Ca}$ & $\mathrm{P}$ & $\mathrm{O}$ \\
\hline $\mathrm{CaOx}$ & 14 & 0 & 86 & 14 & 0 & 86 & 69 & 0 & 31 \\
$\mathrm{HA}$ & 24 & 14 & 62 & 26 & 2 & 72 & 75 & 10 & 14 \\
$\mathrm{DCP}$ & 17 & 17 & 67 & 19 & 2 & 79 & 66 & 15 & 19 \\
\hline
\end{tabular}


Table 5. Percent difference between the contribution of each element to the total X-ray attenuation contribution and volume fraction of each calcium crystal composition.

\begin{tabular}{cccc|ccc|ccc}
\hline & \multicolumn{3}{c|}{ Elemental Isovolume } & \multicolumn{3}{|c|}{ Ionic True Volume } & \multicolumn{3}{|c}{ Covalent True Volume } \\
& $\mathrm{Ca}$ & $\mathrm{P}$ & $\mathrm{O}$ & $\mathrm{Ca}$ & $\mathrm{P}$ & $\mathrm{O}$ & $\mathrm{Ca}$ & $\mathrm{P}$ & $\mathrm{O}$ \\
\hline $\mathrm{CaOx}$ & 71 & 0 & 69 & 71 & 0 & 69 & 8 & 0 & 31 \\
$\mathrm{HA}$ & 53 & 6 & 80 & 50 & 78 & 82 & 2 & 22 & 35 \\
$\mathrm{DCP}$ & 61 & 16 & 15 & 56 & 84 & 80 & 2 & 22 & 65 \\
\hline $\begin{array}{c}\text { Pooled Mean } \\
( \pm \text { std.dev })\end{array}$ & $41 \pm 30$ & & \multicolumn{2}{|c|}{$64 \pm 25$} & & $21 \pm 20$ & \\
\hline
\end{tabular}

Table 6. RMSE and coefficient of determination for each element using the elemental isovolume and true volume assumptions in the elemental decomposition.

\begin{tabular}{c|cccc}
\hline \multicolumn{1}{c}{} & Calibration & $\mathrm{Ca}$ & $\mathrm{P}$ & $\mathrm{O}$ \\
\hline $\begin{array}{c}\text { RMSE } \\
\text { (Percent } \\
\text { Signal) }\end{array}$ & $\begin{array}{c}\text { Isovolume } \\
\text { Ionic } \\
\text { True Volume } \\
\text { Covalent } \\
\text { True Volume }\end{array}$ & 4.80 & 11.50 & 16.62 \\
\hline \multirow{2}{*}{$R^{2}$} & $\begin{array}{c}\text { Isovolume } \\
\text { Ionic } \\
\text { True Volume } \\
\text { Covalent } \\
\text { True Volume }\end{array}$ & 0.90 & 11.01 & 14.65 \\
& 0.77 & 0.74 & 0.17 \\
\hline
\end{tabular}




\section{Figure Captions}

Figure 1. Calculated X-ray attenuation of $\mathrm{Ca}$ (red) and $\mathrm{P}$ (green) for a $120 \mathrm{kVp}$ source with $2 \mathrm{~mm}$ aluminum filtration at thicknesses selected to achieve equivalent total attenuation across the 20$120 \mathrm{keV}$ photon energy spectrum. An intersection point was observed at $\sim 44 \mathrm{keV}$ where the energy dependent attenuation of $\mathrm{P}$ exceeds $\mathrm{Ca}$ at higher photon energies.

Figure 2. Schematic diagram of three example VOIs confined to a maximum dimension $(0.6,1.8$ and $4.2 \mathrm{~mm}$ diameter and length) showing the volume and number of replicates available within the overall sample volume.

Figure 3. Representative image slices of a sample phantom with mixed, or spatially coincident, compositions comprising calcium chloride ranging from 0 to $2.44 \mathrm{M}$ and phosphoric acid ranging from 0 to $2.17 \mathrm{M}$ showing (a) grayscale image from the middle energy bin $(32-80 \mathrm{keV})$ and quantitative material decomposition maps of (b) $\mathrm{Ca}$ (red) and (c) P (green). Grayscale intensities were converted to HU and color intensities were scaled to molar concentrations.

Figure 4. Linear regression of measured versus known concentrations of $\mathrm{Ca}$ (red) and $\mathrm{P}$ (green) in mixed compositions of the homogenous liquid phantom.

Figure 5. Representative image slices of a sample phantom with model $\mu$ cals comprising HA and DCP ranging in concentration from 0 to 7.5 volume percent, and $\mathrm{CaOx}$ ranging from 0 to 11.25 volume percent, including a (a) grayscale image from the middle energy bin $(32-74 \mathrm{keV})$ and quantitative elemental decomposition maps using the elemental isovolumetric calibration showing (b) $\mathrm{Ca}$ (red), (c) $\mathrm{O}$ (blue), (d) $\mathrm{P}$ (green) and (e) the $\mathrm{P} /(\mathrm{Ca}+\mathrm{P})$ ratio. Grayscale intensities were converted to $\mathrm{HU}$ and color intensities were scaled to volume percent or the $\mathrm{P} /(\mathrm{Ca}+\mathrm{P})$ ratio. 
Figure 6. Representative image slices of a sample phantom with model $\mu$ cals comprising HA and DCP ranging in concentration from 0 to 7.5 volume percent, and $\mathrm{CaOx}$ ranging from 0 to 11.25 volume percent, including a (a) grayscale image from the middle energy bin $(32-74 \mathrm{keV})$ and quantitative elemental decomposition maps using the ionic true volume fraction calibration showing (b) $\mathrm{Ca}$ (red), (c) $\mathrm{O}$ (blue), (d) $\mathrm{P}$ (green) and (e) the $\mathrm{P} /(\mathrm{Ca}+\mathrm{P})$ ratio. Grayscale intensities were converted to $\mathrm{HU}$ and color intensities were scaled to volume percent or the $\mathrm{P} /(\mathrm{Ca}+\mathrm{P})$ ratio.

Figure 7. Representative image slices of a sample phantom with model $\mu$ cals comprising HA and DCP ranging in concentration from 0 to 7.5 volume percent, and $\mathrm{CaOx}$ ranging from 0 to 11.25 volume percent, including a (a) grayscale image from the middle energy bin $(32-74 \mathrm{keV})$ and quantitative elemental decomposition maps using the covalent true volume fraction calibration showing (b) $\mathrm{Ca}$ (red), (c) $\mathrm{O}$ (blue), (d) $\mathrm{P}$ (green) and (e) the $\mathrm{P} /(\mathrm{Ca}+\mathrm{P})$ ratio. Grayscale intensities were converted to $\mathrm{HU}$ and color intensities were scaled to volume percent or the $\mathrm{P} /(\mathrm{Ca}+\mathrm{P})$ ratio.

Figure 8. Quantitative analysis of elemental isovolume decomposition showing the AUC for delineation of (a) HA versus $\mathrm{CaOx}$, (b) DCP versus $\mathrm{CaOx}$, and (c) DCP versus HA calcium crystal compositions, using the measured elemental concentrations of Ca (red), P (green), O (blue), and $\mathrm{P} /(\mathrm{Ca}+\mathrm{P})$ (purple), within a VOI of varying size (maximum dimension). The shaded region shows clinically relevant $\mu$ cal dimensions. Dashed lines show AUC levels that provide a strong indicator for the positive group (green) (e.g., HA in $\mathrm{HA}$ versus $\mathrm{CaOx}$ ) and negative group (red) (e.g., $\mathrm{CaOx}$ in $\mathrm{HA}$ versus $\mathrm{CaOx}$ ). A measured AUC of 0.5 (gray dashed line) indicates no ability to distinguish between two compositions.

Figure 9. Quantitative analysis of ionic true volume decomposition showing the AUC for delineation of (a) HA versus $\mathrm{CaOx}$, (b) DCP versus $\mathrm{CaOx}$, and (c) DCP versus HA calcium crystal 
compositions, using the measured elemental concentrations of Ca (red), P (green), O (blue), and $\mathrm{P} /(\mathrm{Ca}+\mathrm{P})$ (purple), within a VOI of varying size (maximum dimension). The shaded region shows clinically relevant $\mu$ cal dimensions. Dashed lines show AUC levels that provide a strong indicator for the positive group (green) (e.g., HA in $\mathrm{HA}$ versus $\mathrm{CaOx}$ ) and negative group (red) (e.g., $\mathrm{CaOx}$ in $\mathrm{HA}$ versus $\mathrm{CaOx}$ ). A measured AUC of 0.5 (gray dashed line) indicates no ability to distinguish between two compositions.

Figure 10. Quantitative analysis of covalent true volume decomposition showing the AUC for delineation of (a) HA versus $\mathrm{CaOx}$, (b) DCP versus $\mathrm{CaOx}$, and (c) DCP versus HA calcium crystal compositions, using the measured elemental concentrations of $\mathrm{Ca}$ (red), $\mathrm{P}$ (green), O (blue), and $\mathrm{P} /(\mathrm{Ca}+\mathrm{P})$ (purple), within a VOI of varying size (maximum dimension). The shaded region shows clinically relevant $\mu$ cal dimensions. Dashed lines show AUC levels that provide a strong indicator for the positive group (green) (e.g., HA in $\mathrm{HA}$ versus $\mathrm{CaOx}$ ) and negative group (red) (e.g., $\mathrm{CaOx}$ in $\mathrm{HA}$ versus $\mathrm{CaOx}$ ). A measured AUC of 0.5 (gray dashed line) indicates no ability to distinguish between two compositions. 


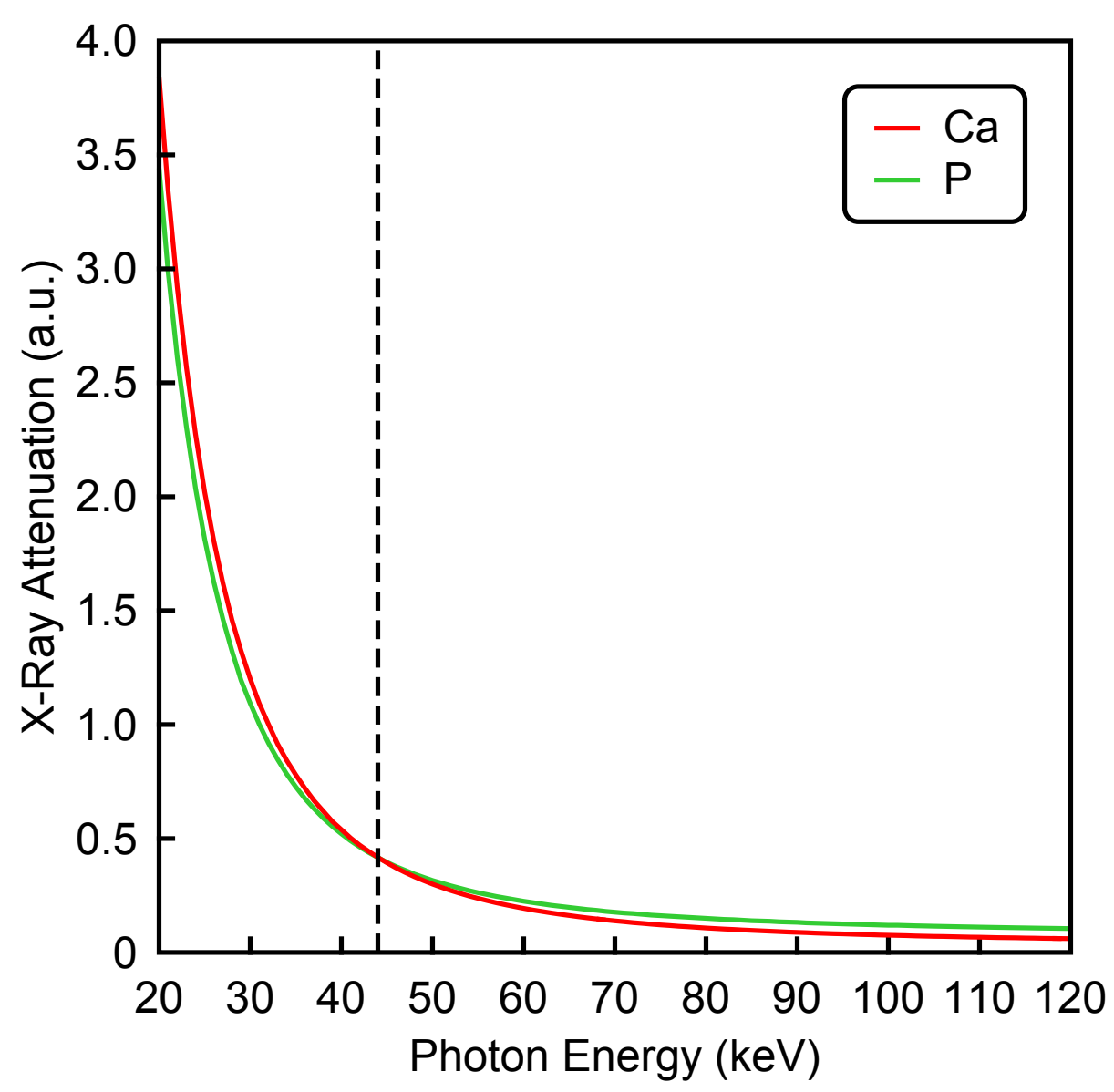


bioRxiv preprint doi: https://doi.org/10.1101/2020.09.16.300509; this version posted September 18, 2020. The copyright holder for this preprint (which was not certified by peer review) is the author/funder, who has granted bioRxiv a license to display the preprint in perpetuity. It is made available under aCC-BY 4.0 International license.

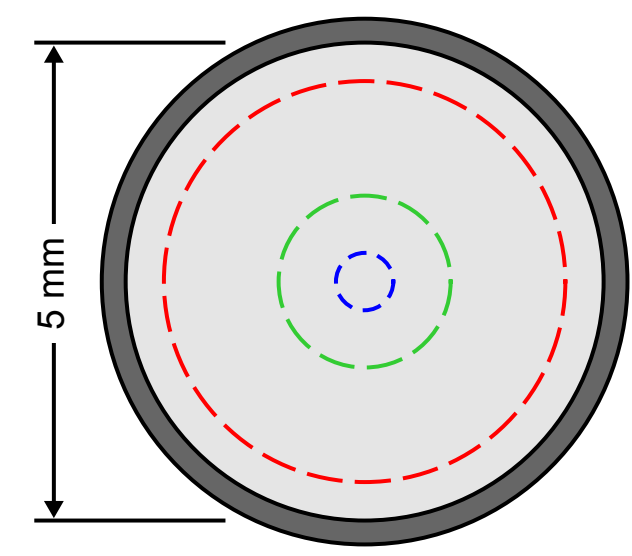

Top View

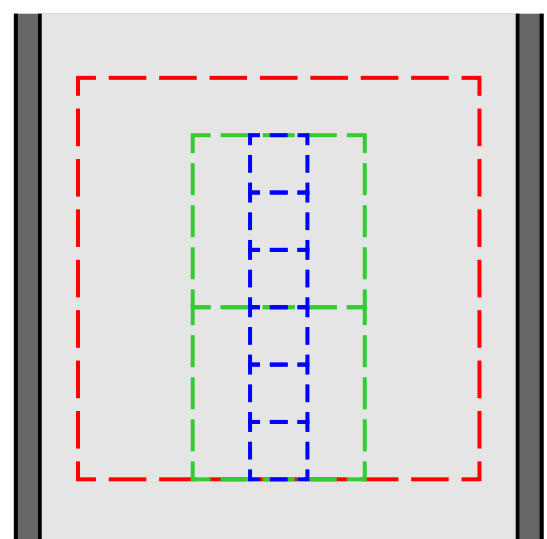

Side View
VOI size:

$---0.6 \mathrm{~mm}$

$-1.8 \mathrm{~mm}$

$--4.2 \mathrm{~mm}$ 
bioRxiv preprint doi: https://doi.org/10.1101/2020.09.16.300509; this version posted September 18, 2020. The copyright holder for this preprint (which was not certified by peer review) is the author/funder, who has granted bioRxiv a license to display the preprint in perpetuity. It is made available under aCC-BY 4.0 International license.

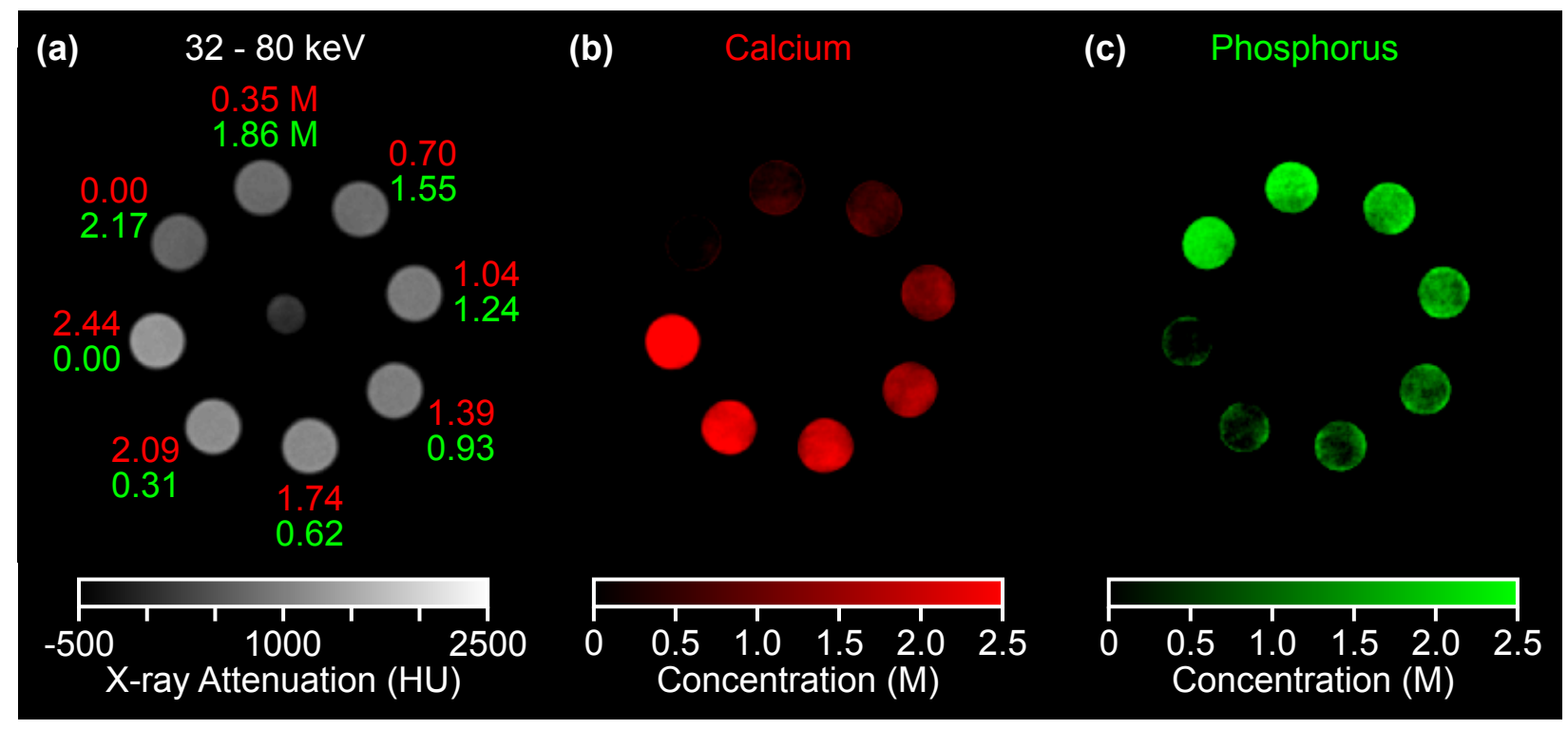


bioRxiv preprint doi: https://doi org/10.1101/2020.09.16.300509; this version posted September 18,2020 . The copyright holder for this preprint (which was not certified by peer review) is the author/funder, who has granted bioRxiv a license to display the preprint in perpetuity. It is made available under aCC-BY 4.0 International license.

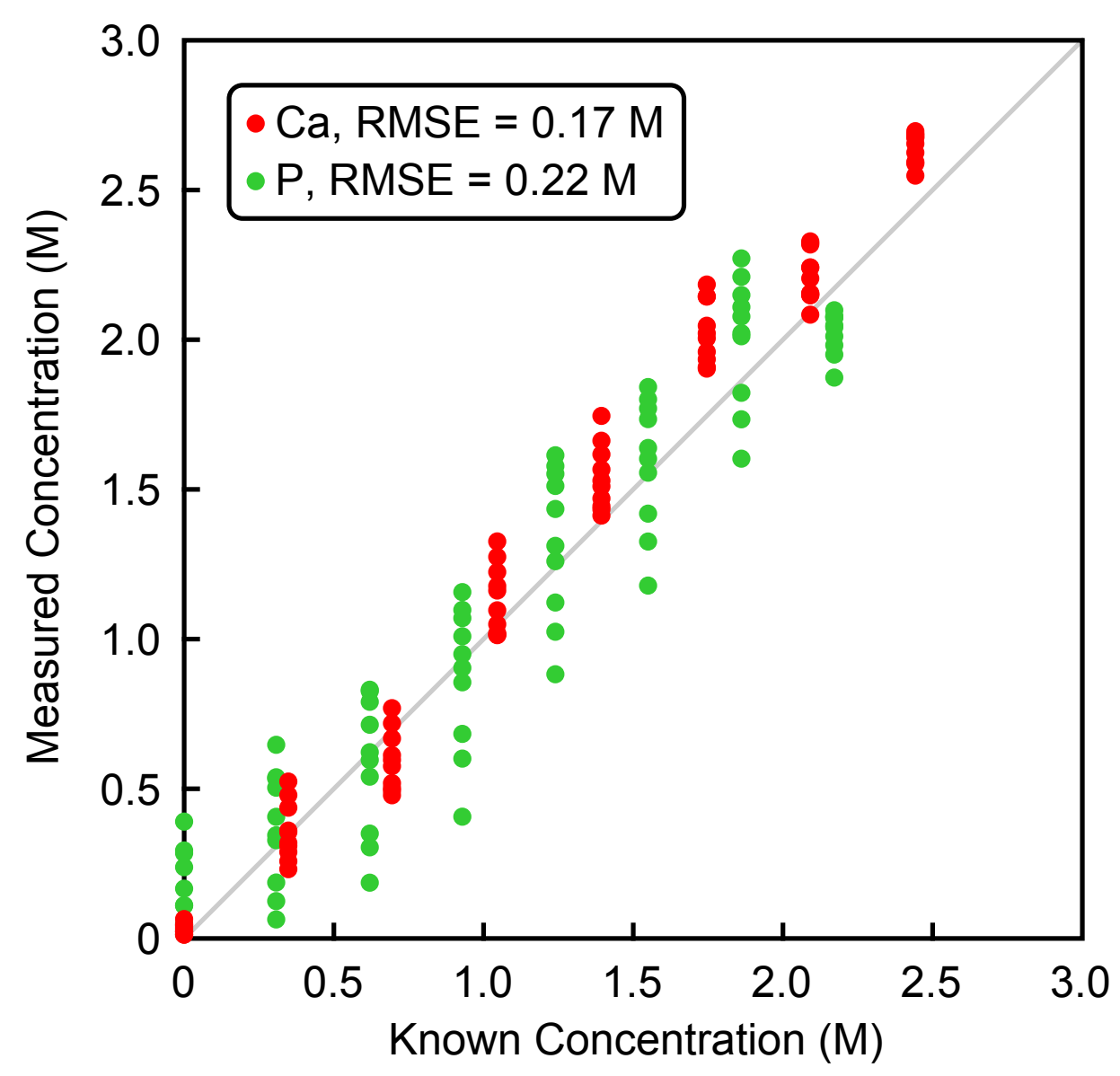




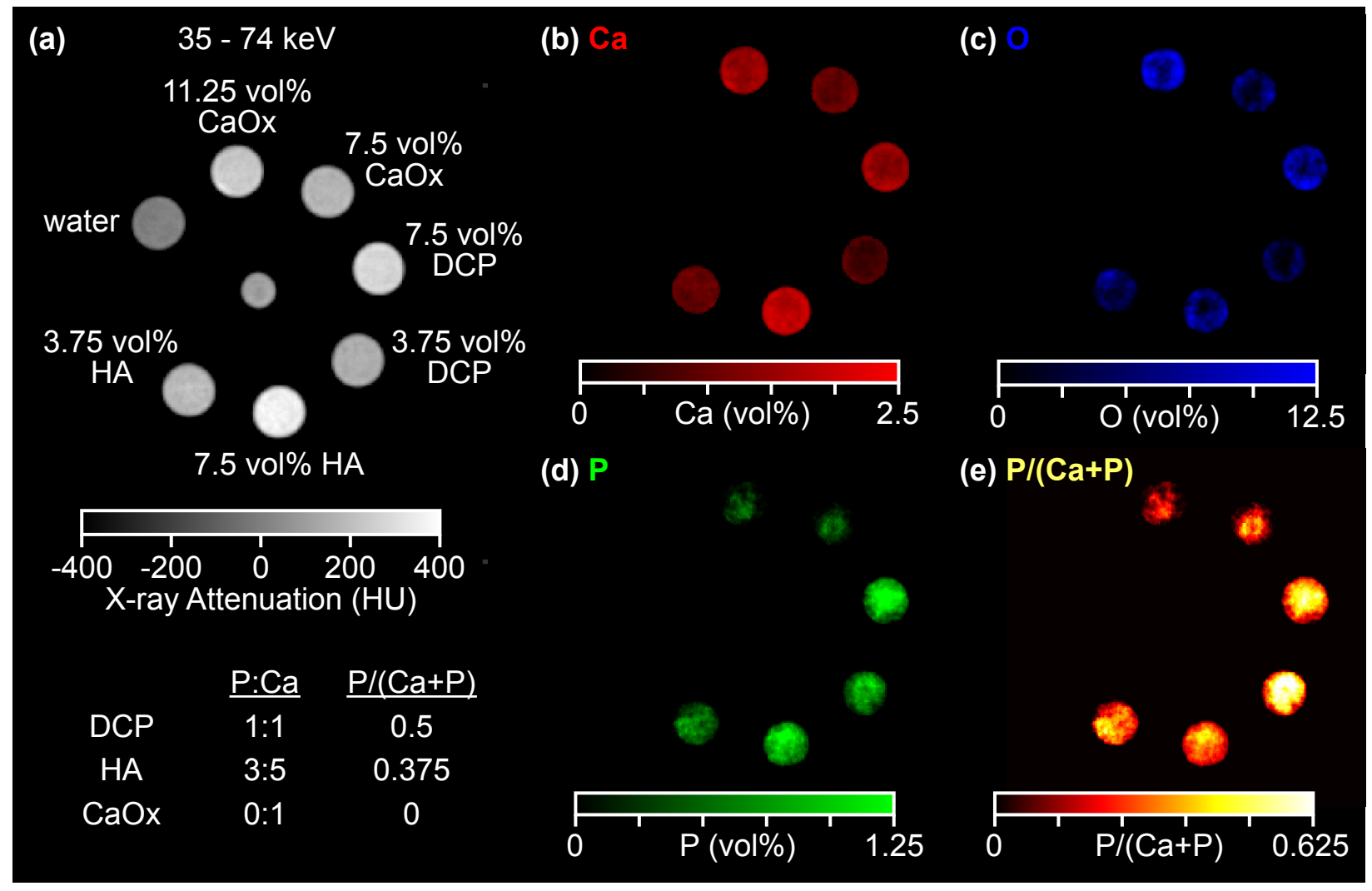

(f)

(g) DCP vs. CaOx

(h) DCP vs. HA
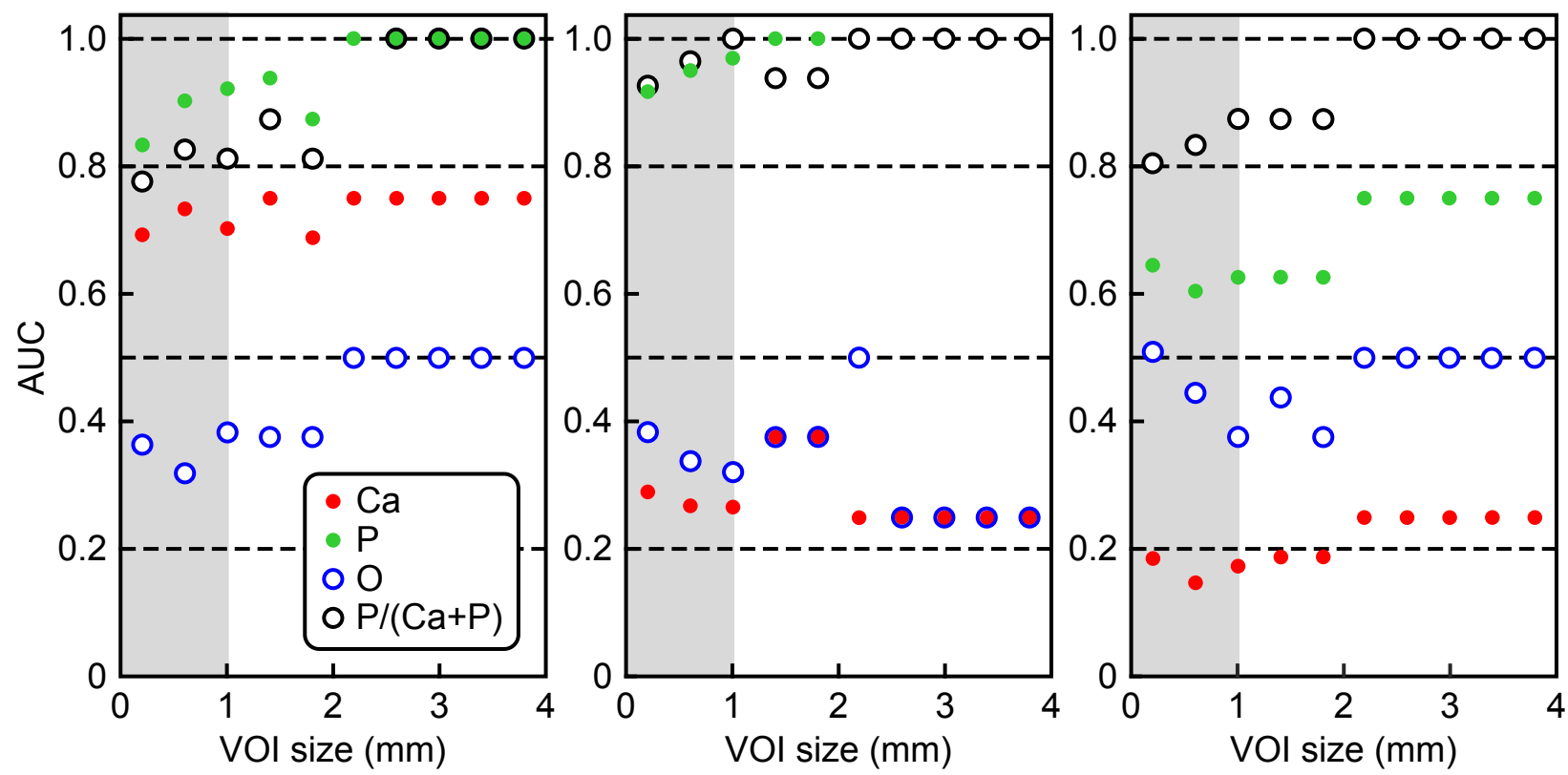


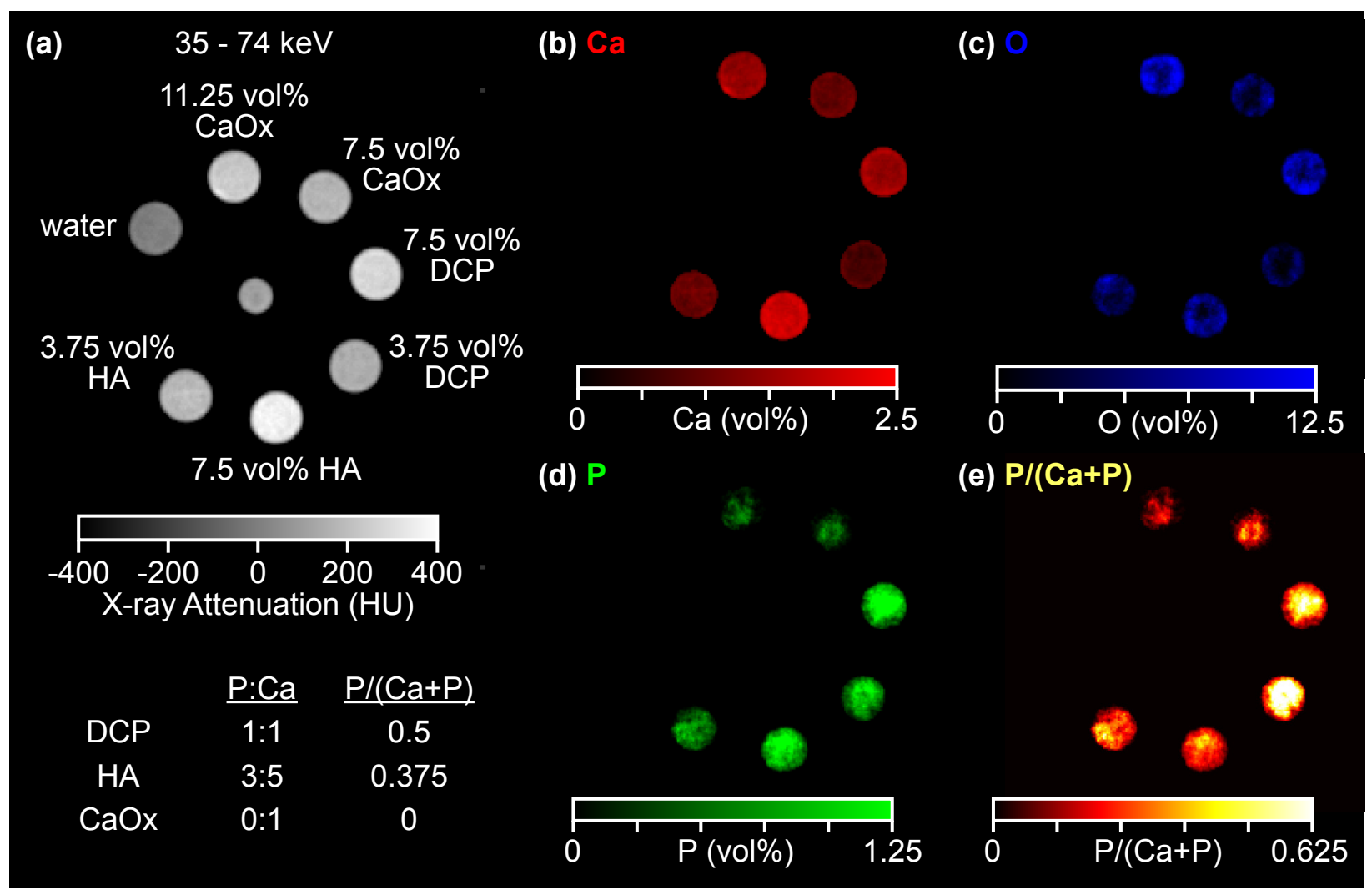

(f)

(g) DCP vs. CaOx

(h)

DCP vs. HA
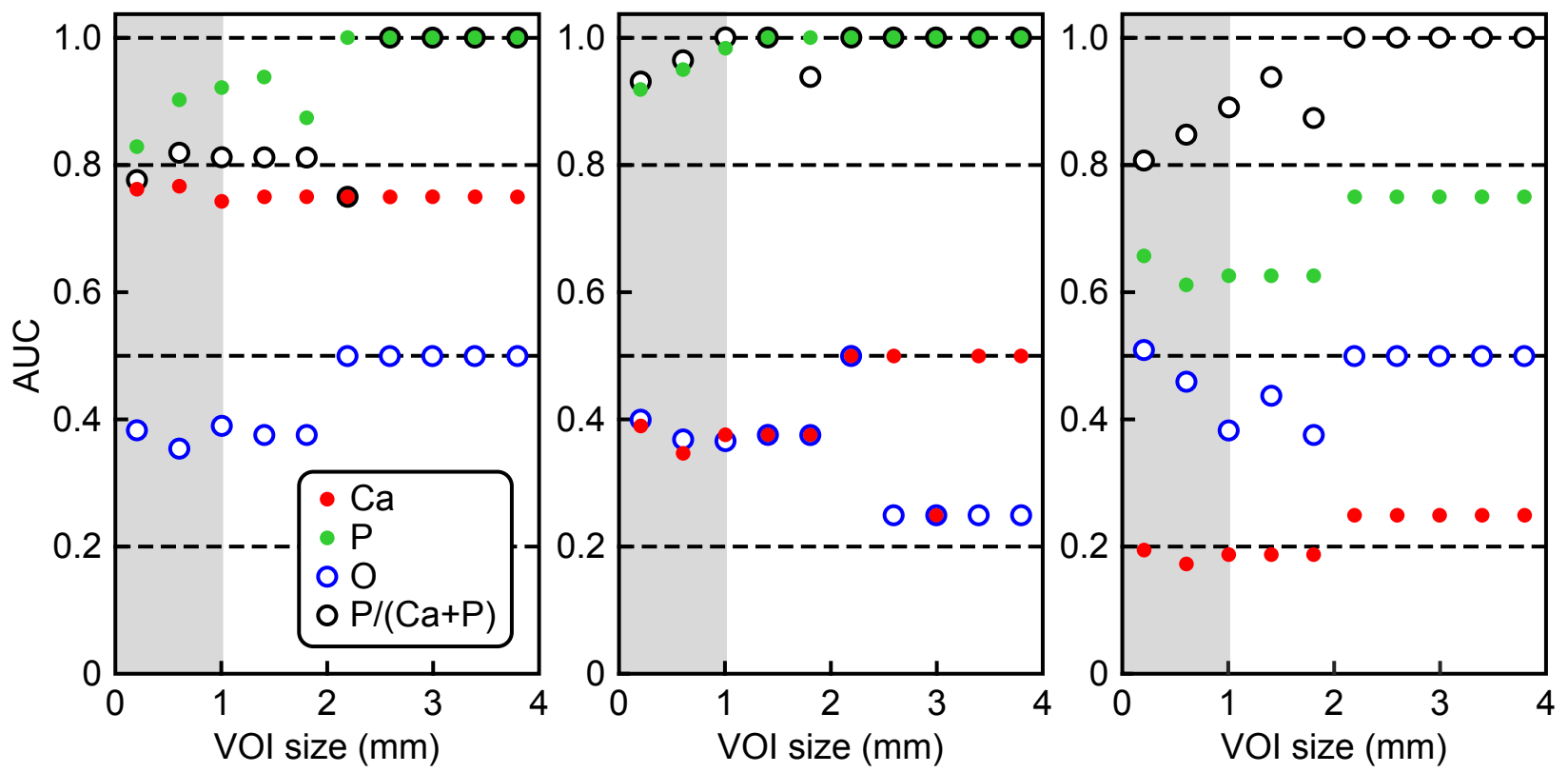

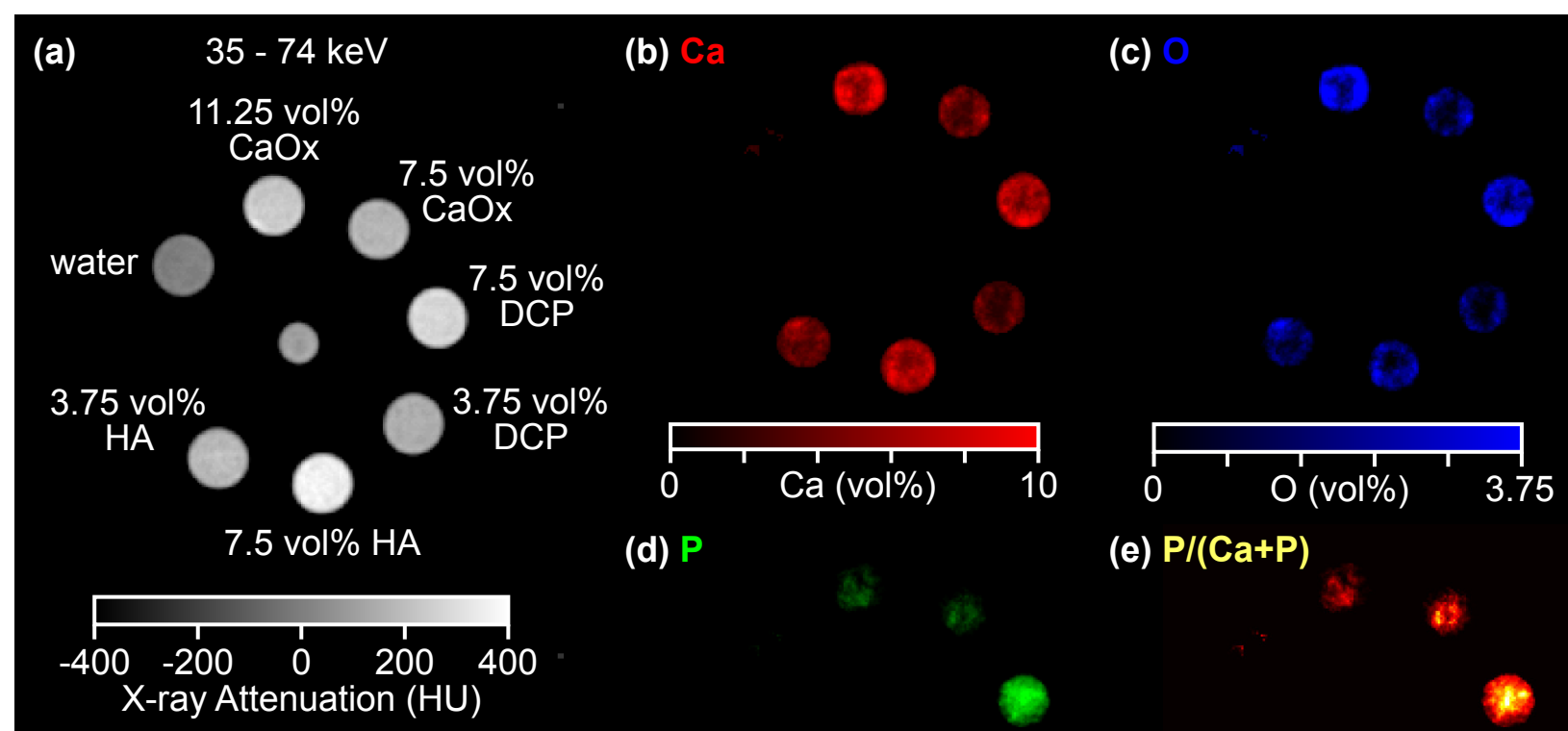

\begin{tabular}{|c|c|c|}
\hline & P:Ca & $\mathrm{P} /(\mathrm{Ca}+\mathrm{P})$ \\
\hline DCP & 1:1 & 0.5 \\
\hline $\mathrm{HA}$ & $3: 5$ & 0.375 \\
\hline $\mathrm{CaOx}$ & $0: 1$ & 0 \\
\hline
\end{tabular}

(f)

(g) DCP vs. CaOx

(h)
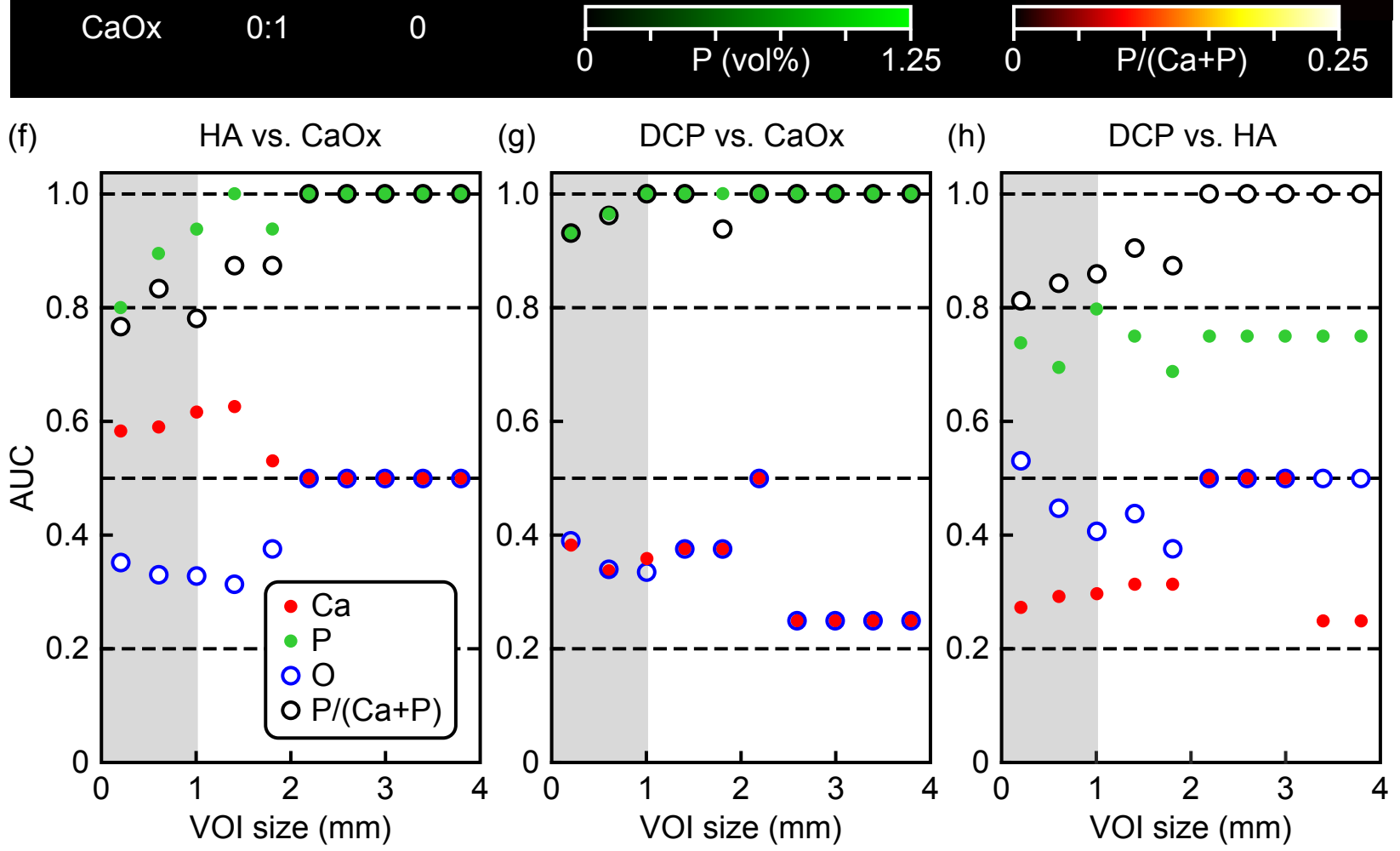

Curtis and Roeder

Figure 7 